\title{
Bicuspid aortic valve repair with external subannular ring: a case report
}

\author{
John J. Kelly ${ }^{1}$, Christopher K. Mehta ${ }^{2}$, Christine Herman ${ }^{3}$, Joshua C. Grimm ${ }^{1}$, Brittany J. Cannon ${ }^{1}$, \\ Nimesh D. Desai ${ }^{1}$, Joseph E. Bavaria ${ }^{1}$ \\ ${ }^{1}$ Division of Cardiovascular Surgery, University of Pennsylvania, Philadelphia, PA, USA; ${ }^{2}$ Division of Cardiac Surgery, Northwestern University, \\ Chicago, IL, USA; ${ }^{3}$ Division of Cardiac Surgery, Dalhousie University, Halifax, Nova Scotia, Canada \\ Correspondence to: Joseph E. Bavaria, MD. 3400 Spruce St., Philadelphia, PA 19104, USA. Email: joseph.bavaria@pennmedicine.upenn.edu.
}

\begin{abstract}
Annuloplasty is a key component of bicuspid aortic valve (BAV) repair for severe aortic insufficiency (AI). Reduction of the annular diameter enhances leaflet coaptation, while annular stabilization prevents subsequent dilation, which can lead to recurrent AI and repair failure. Several techniques have been described, including valve-sparing root reimplantation (VSRR), subcommissural annuloplasty (SCA), suture annuloplasty, and external subannular ring (ESAR). At our institution, BAV repair with VSRR is performed in patients with severe $\mathrm{AI}$ and an aortic root aneurysm $(>4.5 \mathrm{~cm})$. For those presenting with a BAV and severe AI without root enlargement, concomitant SCA is performed when the preoperative annulus is $\leq 27 \mathrm{~mm}$, while ESAR is employed when the annulus measures $>27 \mathrm{~mm}$. A 44-year-old male with known BAV presented to our institution with severe AI and in New York Heart Association (NYHA) Class III heart failure. Pre-procedure transesophageal echocardiogram revealed an annular measurement of $34 \mathrm{~mm}$. Intraoperative inspection of the aortic valve showed a left-right Sievers 1 phenotype with severe calcification confined to the raphe. A BAV repair was performed, which consisted of debridement of calcium from the raphe, triangular resection of the conjoined leaflet, and ESAR. The patient was discharged home after an uneventful post-operative course. At 3-year follow-up, surveillance echocardiogram showed a durable repair without $\mathrm{AI}$ and normal left ventricular function. This case report and associated surgical video demonstrates our step-by-step approach to primary BAV cusp repair with an ESAR.
\end{abstract}

Keywords: Case report; aortic valve; aortic root; repair; external subannular ring

Received: 25 December 2020. Accepted: 22 October 2021.

doi: $10.21037 /$ jovs-20-178

View this article at: https://dx.doi.org/10.21037/jovs-20-178

\section{Introduction}

Repair of a bicuspid aortic valve (BAV) for severe aortic insufficiency (AI) has proven to be a durable alternative to valve replacement (1-4). Annular dilation is an established risk factor for recurrent $\mathrm{AI}$ and repair failure (5-8). Therefore, annuloplasty has become a key component of $\mathrm{BAV}$ repair to both reduce the annular diameter to enhance leaflet coaptation and stabilize the annulus to prevent future dilation. Several techniques have been described, including valve-sparing root reimplantation (VSRR) (1,5-14), subcommissural annuloplasty (SCA) $(5-10,14)$, suture annuloplasty (SA) $(15,16)$, and external subannular ring (ESAR) $(4,5,6,17-22)$.
Our group has previously demonstrated excellent midterm results of primary cusp repair with VSRR for BAV. with severe $\mathrm{AI}$ in the setting of an aortic root aneurysm $(1,6,13,14)$. For patients without aneurysmal degeneration, our group has reported comparable freedom from AI and reduction of left ventricular diameters after repair with concomitant ESAR or SCA depending on annular dimensions (5). Furthermore, ESAR was associated with lower mean transvalvular gradients as well as a greater degree of annular reduction (5). In those undergoing SCA, a large preoperative aortic annulus was predictive of recurrent $\mathrm{AI}(6,14)$.

Accordingly, in patients with a repairable BAV and 


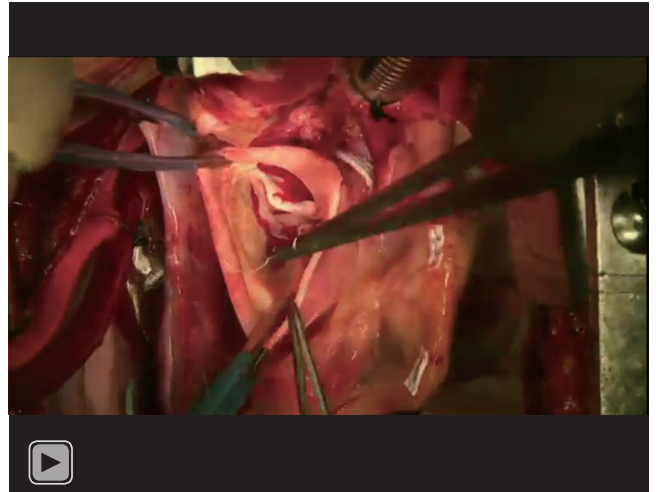

Video 1 Surgical video demonstrating our step-by-step process in performing a bicuspid aortic valve repair with external subannular ring.

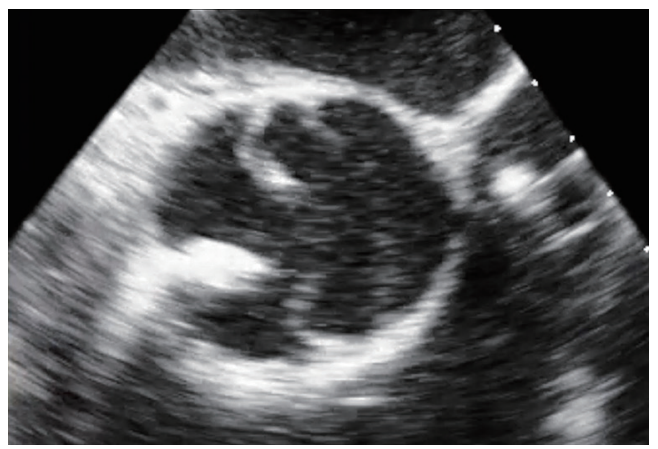

Figure 1 Intra-operative transesophageal echocardiogram showing Sievers Type 1 bicuspid valve with fusion of the right and left coronary cusps and a calcified raphe with a mobile component.

severe AI, our current institutional practice is to perform cusp repair with concomitant VSRR if the sinus segment exceeds $4.5 \mathrm{~cm}$, SCA for preoperative annulus $\leq 27 \mathrm{~mm}$, and ESAR for preoperative annulus $>27 \mathrm{~mm}$. This case report and associated surgical video demonstrate a primary BAV cusp repair with ESAR. We present the following case in accordance with the CARE reporting checklist (Video 1) (available at https://dx.doi.org/10.21037/jovs-20-178).

\section{Case presentation}

A 44-year-old male with past medical history of nephrolithiasis and known BAV presented with severe AI in New York Heart Association (NYHA) Class III heart failure. Transthoracic echocardiogram (TTE) showed a LVEF 45\%, severe left ventricular dilation (LVEDD $7.8 \mathrm{~cm}$ )

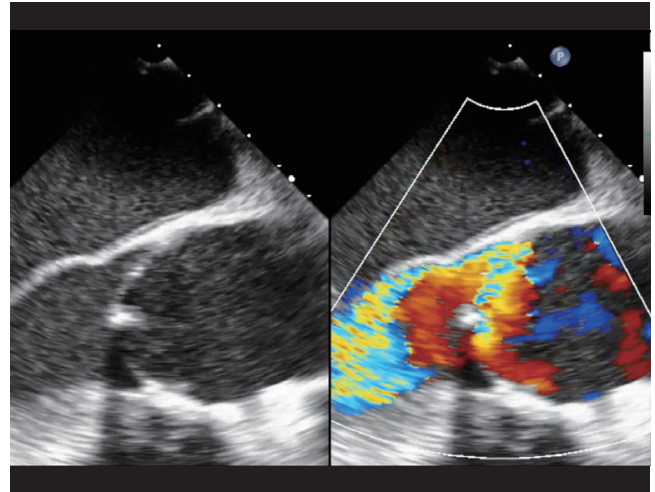

Figure 2 Intra-operative transesophageal echocardiogram showing severe, eccentric aortic insufficiency.

and high-normal aortic dimensions (root $4.0 \mathrm{~cm}$; ascending $3.8 \mathrm{~cm}$ ). Intra-operative, preprocedure transesophageal echocardiogram (TEE) demonstrated a Sievers Type 1 BAV with fusion of the left and right coronary cusps, a calcified raphe with a mobile component, an annular measurement of $34 \mathrm{~mm}$, and severe, eccentric, posteriorly directed AI (Figures 1,2).

Direct visual inspection of the aortic valve confirmed the left-right Sievers 1 phenotype with severe calcification confined to the raphe. The reference cusp had excellent mobility while the conjoined cusp was significantly restricted. There was prolapse of the conjoined cusp, which was responsible for the severe eccentric AI seen on echocardiogram. Following valve analysis, the raphe was released and debrided of calcium, which allowed for significantly increased mobility of the leaflet (Figures 3,4). Free margin equalization was then assessed using interrupted 5-0 polypropylene sutures in the Nodule of Arantius of the reference and conjoined cusps, which demonstrated excess free margin tissue in the conjoined cusp. A triangular resection was performed, which both improved the free margin length and excised much of the diseased, calcified raphe tissue (Figure 5). The triangular resection defect was repaired with interrupted 5-0 polypropylene sutures.

The aortic root was then dissected to the ventriculoaortic junction about 3-4 mm below the annulus, with particular care taken around the coronary arteries (Figure 6). Next, 2-0 plegeted braided polyester sutures were placed in the subannular plane from inside the left ventricular outflow tract to outside. Typically, we use 6 of these sutures for a bicuspid valve ( 3 per cusp). However, 7 were used in this 


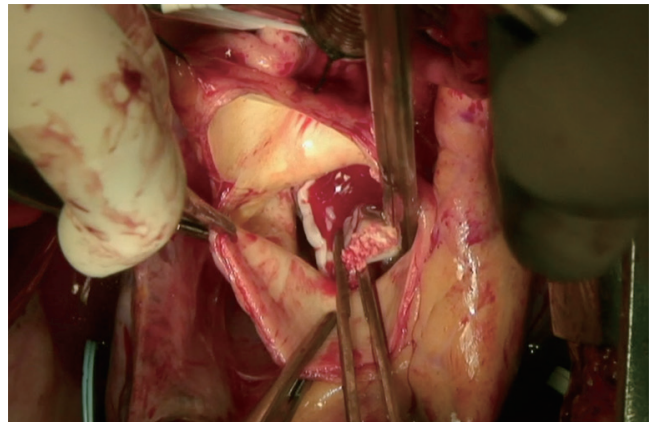

Figure 3 Debridement of calcium from the raphe.

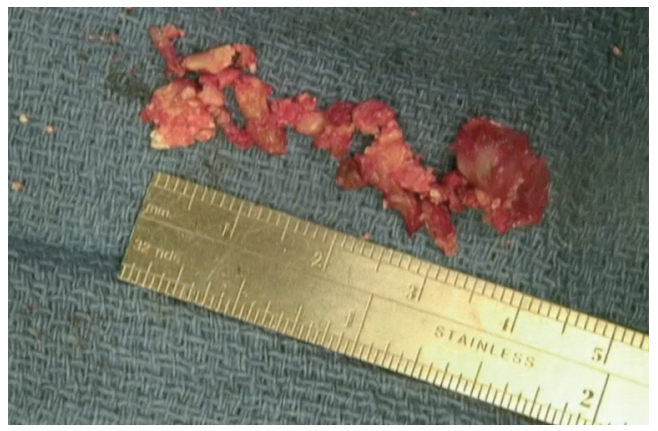

Figure 4 Calcium debrided from the raphe.

case due to the large annular size (3 on the reference cusp; 2 on either side of the raphe on the conjoined cusp). When placing these sutures, particular care was taken to avoid the coronary arteries. The coronaries were probed to ensure patency following suture placement.

Our group's technique for sizing the ESAR has been previously described $(5,6)$. For a BAV with an annulus $>27 \mathrm{~mm}$, we aim to reduce the annular diameter to a physiologic dimension based on the patient's body surface area (BSA) and sex. In general, this corresponds to $23-24 \mathrm{~mm}$ for men and $21 \mathrm{~mm}$ for women. Accordingly, for this patient with a $34 \mathrm{~mm}$ annulus, we targeted an annular diameter of 23-24 mm. We employ a segment of straight Dacron graft for our ESAR repairs based on the following algorithm: targeted annular diameter $=$ Dacron ring size -5 to $6 \mathrm{~mm}$. In this case, we selected a $30 \mathrm{~mm}$ graft. The ring must be cut in order to position it beneath the coronary arteries (Figure 7). After the ring was positioned in the subcoronary plane, it was sewn back together using interrupted 4-0 polypropylene sutures. This reduced the diameter by 2 to $28 \mathrm{~mm}$. The previously placed subannular sutures were then passed through the Dacron ring from inside to outside. Tying

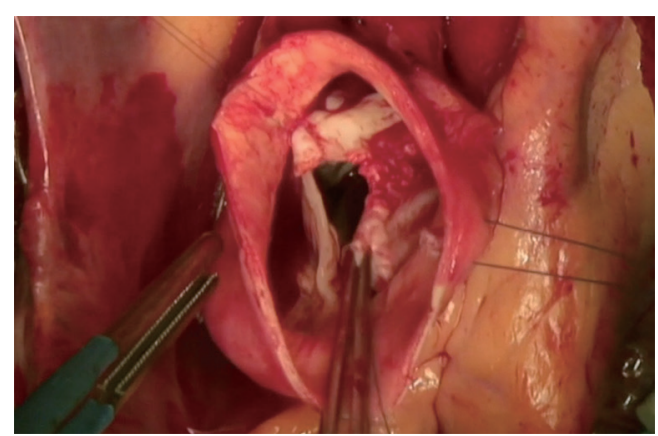

Figure 5 Triangular resection of the conjoined cusp.

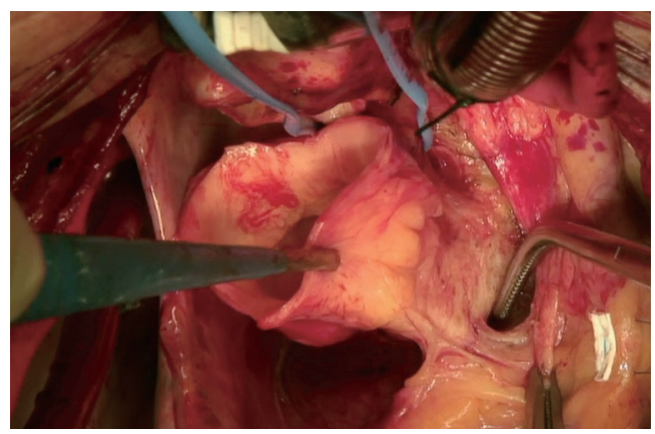

Figure 6 Dissection of the aortic root to the subcoronary plane.

down the subannular sutures further reduced the annulus by 4-5 mm, meeting the goal of $24 \mathrm{~mm}$ (Figure 8).

Secondary valve analysis is then performed as, often times, the annular geometry has been altered after securing the ESAR. In this case, an additional 5-0 polypropylene plication suture was placed at the free margin of the conjoined cusp to further improve free margin equalization. Subsequent saline test with the left ventricular vent at $400 \mathrm{cc} / \mathrm{min}$ demonstrated valve competence. Post-procedure TEE showed a wellfunctioning valve without insufficiency, a coaptation height of $8.5 \mathrm{~mm}$ (goal $>7-8 \mathrm{~mm}$ ), annular reduction to $24 \mathrm{~mm}$, and mean gradient of $8 \mathrm{mmHg}$. The patient was discharged home after an uneventful post-operative course. At 3-year follow-up, he continues to do well. Surveillance TTE shows a durable repair without $\mathrm{AI}$, normal EF, and normal LV diameters.

All procedures performed in studies involving human participants were in accordance with the ethical standards of the University of Pennsylvania, the Health Insurance Portability and Accountability Act and with the Helsinki Declaration (as revised in 2013). Written informed consent was obtained from the patient for publication of this case 


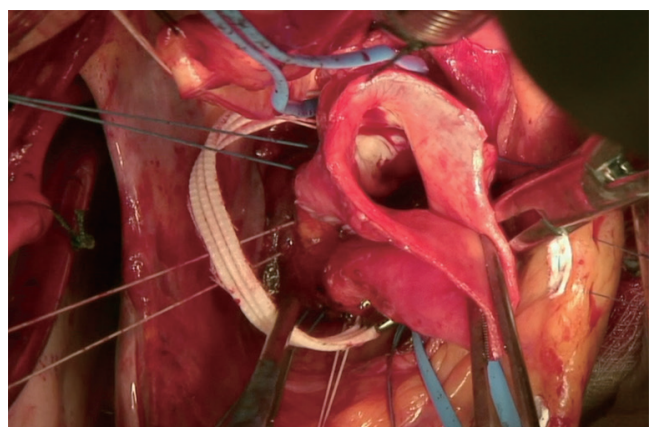

Figure 7 Positioning of the external ring, which consists of a segment of straight Dacron graft, in the subcoronary plane.

report and accompanying images. A copy of the written consent is available for review by the editorial office of this journal.

\section{Discussion}

Primary cusp repair of a BAV with severe AI has proven to be a durable alternative to replacement (1-4). Our approach to BAV cusp repair has been previously described $(1,5,6,13,14)$. After the aorta is transected $1 \mathrm{~cm}$ above the sinotubular junction, valve analysis is performed to assess whether the valve is suitable for repair. If there is severe calcification, large fenestrations, particularly involving the free margins, decreased cusp surface area, or geometric height $<18 \mathrm{~mm}$, repair is deferred in favor of replacement with either a mechanical or biologic prosthesis. As described by Schafers and colleagues, the geometric height of each leaflet is measured intraoperatively using a ruler from the aortic insertion at the nadir of each sinus to the corresponding Nodule of Arantius (23). In the presented case, there were no fenestrations, the calcification was confined to the raphe, and the reference cusp had excellent mobility. Additionally, the conjoined cusp regained sufficient mobility following raphe release and debridement of calcium. To optimize free margin equalization and reduce cusp prolapse, we perform either cusp plication or triangular resection. In this case, we opted for the latter as it would both remove the calcified raphe tissue as well as reduce the excess free margin tissue of the conjoined cusp. We routinely perform secondary valve analysis following a VSSR, SCA or ESAR, to ensure that the coaptation height and valve function remain appropriate. Coaptation height is defined as the zone of cusp apposition during diastole $(24,25)$. Following the termination of cardiopulmonary

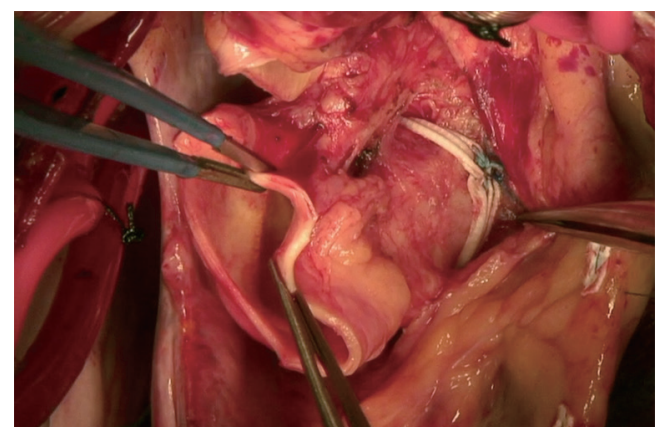

Figure 8 Final position of the external ring after subannular sutures are tied.

bypass, the coaptation height is measured using TEE for a goal of $>7-8 \mathrm{~mm}$.

A large preoperative annular diameter has been shown to be a risk factor for recurrent $\mathrm{AI}$ and repair failure. Kunihara and colleagues reported that preoperative ventriculoaortic junction diameter $>28 \mathrm{~mm}$ was a significant predictor for both late $\mathrm{AI}$ and reoperation in patients with either a tricuspid or bicuspid aortic valve undergoing VSRR or root remodeling (12). Similarly, Navarra and associates reported that a ventriculo-aortic junction $\geq 30 \mathrm{~mm}$ preoperatively and $\geq 25 \mathrm{~mm}$ postoperatively were associated with decreased freedom from recurrent AI $>1+$ after SCA at 6 years ( $<30 \mathrm{~mm}: 74 \%$ vs. $\geq 30 \mathrm{~mm}: 39 \%, \mathrm{P}=0.01 ;<25 \mathrm{~mm}: 80 \%$ $v s . \geq 25 \mathrm{~mm}: 31 \%, \mathrm{P}=0.02)$ (7). By contrast, VSRR resulted in greater annular reduction and ventriculo-aortic junction dimension had no effect on recurrent AI (7). Similarly, our group found that a preoperative aortic annulus $\geq 28 \mathrm{~mm}$ was a significant predictor of recurrent $\mathrm{AI}$ in patients undergoing BAV cusp repair with SCA (14). Compared to SCA, VSRR was associated with improved postoperative and 2-year gradients as well as freedom from AI exceeding $1+(92 \% \pm 6 \%$ vs. $62 \% \pm 10 \%, \mathrm{P}=0.03)(14)$. DeKerchove and colleagues also reported that compared to BAV, VSRR was associated with improved freedom from reoperation $(100 \%$ vs. $90 \% \pm 8 \% ; \mathrm{P}=0.025)$ and recurrent $\mathrm{AI}>2+(100 \%$ vs. $77 \% \pm 14 \% ; \mathrm{P}=0.002)$ at 6 years (8). While the circumferential annuloplasty of the VSRR appears to provide greater durability than SCA, performing a VSRR in patients without an aortic root aneurysm is controversial.

One alternative to VSRR is the addition of a suture annuloplasty (SA) to isolated BAV repair as described by Schneider and colleagues, which resulted in significant improvement in durability with 5 -year freedom from reoperation of $92.6 \%$ in the SA group compared to $73.2 \%$ in 
the control group [of which 59.6\% had SCA ( $\mathrm{P}=0.0006)$ ] (15). Lansac and colleagues have utilized a subvalvular external ring in cases where the aortic annulus measures $\geq 25 \mathrm{~mm}$ in patients with either a bicuspid or tricuspid aortic valve undergoing isolated valve repair, supracoronary graft for an ascending aortic aneurysm, or root remodeling for a root aneurysm (17-21). In cases of isolated valve repair for severe AI, Lansac and colleagues also place an external ring at the sinotubular junction in addition to the subvalvular external ring (19). At 7 years, freedom from reoperation was $90.5 \%$ for root remodeling with subvalvular annuloplasty ring, $100 \%$ for ascending aortic replacement with subvalvular annuloplasty ring, and $97.5 \%$ for isolated valve repair with subvalvular or both supra- and subvalvular annuloplasty rings with no difference between bicuspid and tricuspid valves (21). Freedom from AI grade $\geq 3$ was $93.1 \%, 100 \%$, and $82.2 \%$, respectively (21). While initially utilizing a homemade Dacron ring similar to ours, Lansac and colleauges also use a calibrated expansile aortic ring (ExtraAortic; CORONEO, Inc, Montreal, QC, Canada) which is undersized by one size relative to the measured native annulus diameter (i.e., $25 \mathrm{~mm}$ external ring for annulus $25-27 \mathrm{~mm})(19)$.

For patients with a repairable BAV presenting with severe AI, our institutional practice is to perform a BAV cusp repair with concomitant VSRR if there is an aortic root aneurysm $(>4.5 \mathrm{~cm})$, SCA when the preoperative annulus is $\leq 27 \mathrm{~mm}$, and ESAR for preoperative annulus $>27 \mathrm{~mm}$. The decision to use $>27 \mathrm{~mm}$ as our threshold for performing ESAR instead of SCA is based on our group's prior study of SCA, in which we found that SCA performed in an annulus $\leq 27 \mathrm{~mm}$ was stable over time with minimal midterm AI, whereas SCA in a preoperative annulus $\geq 28$ was predictive of recurrent AI grade $>1+$ and associated with significantly lower freedom from AI grade $>1+$ at 5 years (14). More recently, our group reported comparable freedom from $\mathrm{AI}$ and reduction of left ventricular diameters after BAV repair with concomitant ESAR $(n=20)$ or SCA $(\mathrm{n}=38)$, while the former was associated with lower mean transvalvular gradients as well as a greater degree of annular reduction (5). In their series of ESAR, Lansac and colleagues reported an annular reduction of $-5.4 \pm 3.3 \mathrm{~mm}$ (21), which is comparable to the $-5.1 \pm 2.7 \mathrm{~mm}$ observed in ours (5). In the presented case of a 44-year-old male with preoperative annulus measuring $34 \mathrm{~mm}$ and severe AI, BAV cusp repair with ESAR was performed with excellent result at 3 years.

In conclusion, annuloplasty is an essential component of BAV repair. Annular reduction improves leaflet coaptation while annular stabilization prevents subsequent dilation, which can lead to recurrent AI and, ultimately, repair failure. Several techniques have been described, including VSRR, SCA, and ESAR. This case report and associated surgical video demonstrates our step-by-step approach to primary BAV cusp repair with an ESAR.

\section{Acknowledgments}

Funding: None.

\section{Footnote}

Provenance and Peer Review: This article was commissioned by the Guest Editors (Roberto Di Bartolomeo, Davide Pacini, Mohamad Bashir) for the series "Best Video Presentation Prize for the 10th Postgraduate Course on "Surgery of the Thoracic Aorta" in Bologna" published in Fournal of Visualized Surgery. The article has undergone external peer review.

Reporting Checklist: The authors have completed the CARE reporting checklist. Available at https://dx.doi. org/10.21037/jovs-20-178

Peer Review File: Available at https://dx.doi.org/10.21037/ jovs-20-178

Conflicts of Interest: All authors have completed the ICMJE uniform disclosure form (available at https://dx.doi. org/10.21037/jovs-20-178). The series "Best Video Presentation Prize for the 10th Postgraduate Course on "Surgery of the Thoracic Aorta" in Bologna" was commissioned by the editorial office without any funding or sponsorship. The authors have no other conflicts of interest to declare.

Ethical Statement: the authors are accountable for all aspects of the work in ensuring that questions related to the accuracy or integrity of any part of the work are appropriately investigated and resolved. All procedures performed in studies involving human participants were in accordance with the ethical standards of the University of Pennsylvania, the Health Insurance Portability and Accountability Act and with the Helsinki Declaration (as revised in 2013). Written informed consent was obtained from the patient for publication of this case report and accompanying images. A copy of the written consent is 
available for review by the editorial office of this journal.

Open Access Statement: This is an Open Access article distributed in accordance with the Creative Commons Attribution-NonCommercial-NoDerivs 4.0 International License (CC BY-NC-ND 4.0), which permits the noncommercial replication and distribution of the article with the strict proviso that no changes or edits are made and the original work is properly cited (including links to both the formal publication through the relevant DOI and the license). See: https://creativecommons.org/licenses/by-nc-nd/4.0/.

\section{References}

1. Vallabhajosyula P, Szeto WY, Habertheuer A, et al. Bicuspid Aortic Insufficiency With Aortic Root Aneurysm: Root Reimplantation Versus Bentall Root Replacement. Ann Thorac Surg 2016;102:1221-8.

2. Svensson LG, Batizy LH, Blackstone EH, et al. Results of matching valve and root repair to aortic valve and root pathology. J Thorac Cardiovasc Surg 2011;142:1491-8.e7.

3. Ashikhmina E, Sundt TM 3rd, Dearani JA, et al. Repair of the bicuspid aortic valve: a viable alternative to replacement with a bioprosthesis. J Thorac Cardiovasc Surg 2010;139:1395-401.

4. Lansac E, Bouchot O, Arnaud Crozat E, et al. Standardized approach to valve repair using an expansible aortic ring versus mechanical Bentall: early outcomes of the CAVIAAR multicentric prospective cohort study. J Thorac Cardiovasc Surg 2015;149:S37-45.

5. Ko H, Bavaria JE, Habertheuer A, et al. Functional Outcomes of Type I Bicuspid Aortic Valve Repair With Annular Stabilization: Subcommissural Annuloplasty Versus External Subannular Aortic Ring. Ann Thorac Surg 2019;107:68-75.

6. Habertheuer A, Milewski RK, Bavaria JE, et al. Predictors of Recurrent Aortic Insufficiency in Type I Bicuspid Aortic Valve Repair. Ann Thorac Surg 2018;106:1316-24.

7. Navarra E, El Khoury G, Glineur D, et al. Effect of annulus dimension and annuloplasty on bicuspid aortic valve repair. Eur J Cardiothorac Surg 2013;44:316-22; discussion 322-3.

8. de Kerchove L, Boodhwani M, Glineur D, et al. Valve sparing-root replacement with the reimplantation technique to increase the durability of bicuspid aortic valve repair. J Thorac Cardiovasc Surg 2011;142:1430-8.

9. El Khoury G, Vanoverschelde JL, Glineur D, et al. Repair of bicuspid aortic valves in patients with aortic regurgitation. Circulation 2006;114:I610-6.

10. Boodhwani M, de Kerchove L, Glineur D, et al. Repair of regurgitant bicuspid aortic valves: a systematic approach. J Thorac Cardiovasc Surg 2010;140:276-284.e1.

11. Sultan I, Komlo CM, Bavaria JE. How I Teach a Valve-Sparing Root Replacement. Ann Thorac Surg 2016;101:422-5.

12. Kunihara T, Aicher D, Rodionycheva S, et al. Preoperative aortic root geometry and postoperative cusp configuration primarily determine long-term outcome after valvepreserving aortic root repair. J Thorac Cardiovasc Surg 2012;143:1389-95.

13. Vallabhajosyula P, Komlo C, Szeto WY, et al. Root stabilization of the repaired bicuspid aortic valve: subcommissural annuloplasty versus root reimplantation. Ann Thorac Surg 2014;97:1227-34.

14. Vallabhajosyula P, Komlo CM, Szeto WY, et al. Aortic Annulus Diameter Affects Durability of the Repaired Bicuspid Aortic Valve. J Heart Valve Dis 2015;24:412-9.

15. Schneider U, Hofmann C, Aicher D, et al. Suture Annuloplasty Significantly Improves the Durability of Bicuspid Aortic Valve Repair. Ann Thorac Surg 2017;103:504-10.

16. Aicher D, Schneider U, Schmied W, et al. Early results with annular support in reconstruction of the bicuspid aortic valve. J Thorac Cardiovasc Surg 2013;145:S30-4.

17. Youssefi P, Zacek P, Debauchez M, et al. Valve-Sparing Aortic Root Replacement Using the Remodeling Technique With Aortic Annuloplasty: Bicuspid Valves With Repair of Specific Lesion Sets: How I Teach It. Ann Thorac Surg 2019;108:324-33.

18. Youssefi P, Brega C, Shraer N, et al. Isolated Bicuspid Aortic Valve Repair With Double Annuloplasty: How I Teach It. Ann Thorac Surg 2019;108:1596-604.

19. Lansac E, Di Centa I, Sleilaty G, et al. Remodeling root repair with an external aortic ring annuloplasty. J Thorac Cardiovasc Surg 2017;153:1033-42.

20. Lansac E, Di Centa I, Vojacek J, et al. Valve sparing root replacement: the remodeling technique with external ring annuloplasty. Ann Cardiothorac Surg 2013;2:117-23.

21. Lansac E, Di Centa I, Sleilaty G, et al. Long-term results of external aortic ring annuloplasty for aortic valve repair. Eur J Cardiothorac Surg 2016;50:350-60.

22. Boyer K. When Epilepsy Grows Up.... Epilepsy Curr 2019;19:99-100.

23. Schäfers HJ, Schmied W, Marom G, et al. Cusp height in aortic valves. J Thorac Cardiovasc Surg 2013;146:269-74.

24. Berrebi A, Monin JL, Lansac E. Systematic 
echocardiographic assessment of aortic regurgitationwhat should the surgeon know for aortic valve repair? Ann Cardiothorac Surg 2019;8:331-41.

doi: 10.21037/jovs-20-178

Cite this article as: Kelly JJ, Mehta CK, Herman C, Grimm JC, Cannon BJ, Desai ND, Bavaria JE. Bicuspid aortic valve repair with external subannular ring: a case report. J Vis Surg 2021.
25. Vanoverschelde JL, van Dyck M, Gerber B, et al. The role of echocardiography in aortic valve repair. Ann Cardiothorac Surg 2013;2:65-72. 